\title{
Childhood leukaemia presenting in the central nervous system
}

\author{
JOHN GRAHAM POLE \\ From the University Department of Child Health and The Royal Hospital for Sick Children, Glasgow
}

Graham Pole, J. (1973). Archives of Disease in Childhood, 48, 867. Childhood leukaemia presenting in the central nervous system. Four children are described with acute leukaemia of the stem cell variety that presented with cerebral manifestations. The clinical course was practically unaffected by cytotoxic therapy.

The cytology of other cases with cerebral involvement at the time of initial diagnosis was reviewed. Whereas in lymphoblastic leukaemia CNS involvement is rare when the disease first presents but common at later stages, the reverse is the case in the other forms of acute leukaemia in childhood. A theory is put forward to account for these facts.

The prevalence of central nervous system (CNS) infiltration among populations of leukaemic children is frequently attributed to lengthening survival times (Pierce, 1962; Hyman et al., 1965; Evans, Gilbert, and Zandstra, 1970). There is indirect evidence that CNS seeding occurs at the time of initial illness (West et al., 1972), with clinical effects following after an interval that is related to the number of leukaemic cells gaining entry and their replication rates (Hardisty and Norman, 1967; Melhorn et al., 1970). The effect of cerebral involvement on the course of the subsequent haematological disease remains unresolved (Pinkel et al., 1972) but is almost certainly an adverse one (Johnson, 1964; Aur et al., 1972; Evans et al., 1970).

Data are presented here of 4 children who each presented a picture of intracerebral neoplasia, all of whom were subsequently found to have acute leukaemia of uniformly undifferentiated type, and none of whom showed more than a transient response to therapy.

\section{Case reports}

Case 1. A 3-year-old male was admitted with facial pain, irritability, and the sudden appearance of a squint. He was found to have bilateral ptosis, sluggish pupil reactions, and paresis of conjugate upward gaze. Systemic and neurological examination was otherwise normal, and an upper brain stem lesion was suspected. Investigations included $\mathrm{Hb} 11 \cdot 2 \mathrm{~g} / 100 \mathrm{ml}$, platelets 142,000 , WBC 14,500 , neutrophils 4480 , lymphocytes

Received 23 May 1973.
$9135 / \mathrm{mm}^{3}$; skull and skeletal $x$-rays and intravenous pyelography normal; urinary catecholamine excretion $4.4 \mathrm{mg} / 24 \mathrm{hr}$; EEG normal record. On transfer to the regional Neurosurgical Unit (Professor B. Jennett), he was found to have, in addition to bilateral ptosis and gaze palsy, fixed dilated pupils and a right oculomotor nerve palsy. Thereafter, weakness of facial and bulbar muscles developed. CSF examination and iophendylate ventriculography were normal, and a pontine glioma or possible brain stem encephalitis was suspected. 2 weeks later oral ulceration and increasing pallor prompted re-examination of the blood which showed thrombocytopenia and abnormal white cells. On readmission to this hospital he was pale and ill, with mouth ulcers, multiple ecchymoses, hepatosplenomegaly, and enlarged kidneys. The eye signs were unchanged, but the limbs were flaccid and plantar responses were extensor. Peripheral blood showed $\mathrm{Hb} 7 \cdot 2 \mathrm{~g} / 100 \mathrm{ml}$, platelets 17,000 , WBC 21,200 , neutrophils 1060 , blasts $3820 / \mathrm{mm}^{3}$. Marrow smears showed normal cell elements to be largely replaced by primitive cells which were negative to Periodic Acid Schiff (PAS) and Sudan Black stains (SB), contained no Auer rods, showed no tendency to clump, and had the morphology of acute undifferentiated stem cell leukaemia. Repeat skeletal $x$-rays showed infiltrative changes at the metaphyses. Treatment was started with vincristine $0.7 \mathrm{mg}$ once and prednisone 40 $\mathrm{mg}$ daily, but he died 4 days later, 6 weeks after the onset of his symptoms.

At necropsy the brain showed widespread meningeal infiltration with leukaemic cells and perivascular cuffing, and involvement of the extraocular tissues, retina, and pituitary. There was leukaemic involvement of lungs, myocardium, pancreas, thyroid, gall bladder, and stomach, and massive infiltration of liver, spleen, lymph glands, kidneys, and bone marrow. 
Case 2. A 4-year-old male was admitted to another hospital with headache, vomiting, and recent deterioration of vision. There was impaired visual acuity, more marked on the left, but no other abnormalities on neurological or systemic examination. Investigations showed $\mathrm{Hb} 12 \cdot 4 \mathrm{~g} / 100 \mathrm{ml}$, WBC 10,400 , neutrophils 3535 , lymphocytes $5510 / \mathrm{mm}^{3}$, platelets and film normal; skull $x$-ray and EEG normal; CSF under normal pressure, containg no cells and a protein of 15 $\mathrm{mg} / 100 \mathrm{ml}$. On transfer to the regional Neurosurgical Unit, he was found to have bilateral impairment of vision and diminished pupil responses. One week later proptosis was noted, the left pupil becoming fixed and the right more sluggish. Repeat EEG showed right temporal and deep midline dysfunction, but bifrontal burr hole exploration, CSF examination, ventriculography, and air encephalography were all normal. Subsequent re-examination of the blood revealed $\mathrm{Hb} 5 \cdot 8$ $\mathrm{g} / 100 \mathrm{ml}$, platelet count $<10,000$, WBC $12,100 / \mathrm{mm}^{3}$ including many blast cells. On transfer to this hospital he was pale and wasted; the left eye was blind and had limited movement, and there were signs of bilateral retrobulbar neuritis and globe compression. Neurological examination was otherwise normal and there was no liver, spleen, or lymph node enlargement. The blood showed $\mathrm{Hb} 3 \cdot 8 \mathrm{~g} / 100 \mathrm{ml}$, platelets 10,000 , WBC 11,700, neutrophils 2550 , blast cells $1750 / \mathrm{mm}^{3}$. Marrow smears were of increased cellularity, with reduction of normal cell elements and $92 \%$ blast forms present. These cells were morphologically undifferentiated, showed no tendency to clump, and contained no Auer rods and were PAS and SB negative. Skeletal $x$-rays were suggestive of metaphyseal infiltration; urinary catecholamine excretion was normal.

Acute undifferentiated stem cell leukaemia was diagnosed and treatment started with rubidomycin 20 $\mathrm{mg}$ twice weekly, cytosine arabinoside $50 \mathrm{mg}$ daily for 5 days ( 2 courses) with a subsequent reduction in the orbital swelling and improvement in optic nerve function. Repeat EEGs showed a continuing diffuse abnormality. After 2 weeks the blood showed $\mathrm{Hb} 11 \cdot 2$ $\mathrm{g} / 100 \mathrm{ml}$, platelets 70,000 , WBC 2800 , neutrophils 1200 , lymphocytes $1430 / \mathrm{mm}^{3}$, and no blast cells. Repeat marrow smears showed regenerating normal cell elements and 2 to $3 \%$ blast cells. A third course of rubidomycin and cytosine was given, but within 2 weeks immature cells reappeared in the peripheral blood, coincident with rapid clinical deterioration, and he died 12 weeks after the onset of his symptoms. Permission for necropsy examination was not given.

Case 3. An 8-year-old male was admitted to another hospital with headaches, double vision, and slurred speech. He was wasted, there was a right proptosis and abducent nerve palsy, but neurological and systemic examination was otherwise normal. Investigations showed $\mathrm{Hb} 9 \cdot 2 \mathrm{~g} / 100 \mathrm{ml}$, WBC 7100 , neutrophils 3200 , lymphocytes $3400 / \mathrm{mm}^{3}$, platelets and film normal. CSF contained 250 mononuclear cells $/ \mathrm{mm}^{3}$, protein $76 \mathrm{mg}$ and sugar $31 \mathrm{mg} / 100 \mathrm{ml}$, sterile on culture. 1:1000 tuberculin test negative (BCG scar present). On transfer to the regional Neurosurgical Unit these findings were confirmed, and a left proptosis and gaze palsy were suspected in addition. Urinary catecholamine excretion and repeat full blood count were normal, and biopsy of an axillary lymph node gave normal histology. Subsequent mairow examination, however showed primitive cells of uncertain type. He was transferred to this hospital where he was seen to be cachectic, with enlargement of liver, spleen, and lymph nodes. There were signs of retrobulbar neuritis and bilateral proptosis, a coarse right-sided nystagmus, and impaired hearing in the right ear. Investigations included $\mathrm{Hb} 7 \cdot 0 \mathrm{~g} / 100 \mathrm{ml}$, platelets 97,000 , WBC 16,350, neutrophils 4580 , blast cells $2780 / \mathrm{mm}^{3}$; urinary catecholamines $0.54 \mathrm{mg} / 100 \mathrm{ml}$; and intravenous pyelography showed renal enlargement consistent with leukaemic infiltration. Marrow smears showed almost total replacement of normal elements by very primitive cells that were PAS and SB negative, did not tend to clump, and contained no Auer rods. Acute undifferentiated stem cell leukaemia was diagnosed and treatment started with rubidomycin $20 \mathrm{mg}$ weekly (times 3 ), vincristine $1.75 \mathrm{mg}$ weekly (times 3 ), asparaginase 10,000 units daily (times 7), and prednisone $60 \mathrm{mg}$ daily. There was temporary clinical improvement, but recurring vomiting and headache prompted repeat lumbar puncture. CSF had an opening pressure of 240 $\mathrm{mm}$ and contained 69 blast cells $/ \mathrm{mm}^{3}$. 5 injections of intrathecal methotrexate were given over the next 8 weeks. He remained marasmic and his biopsy site was persistently infected. Signs developed of upper brain stem involvement, with sluggish pupil reactions and paresis of upward gaze, and his profound emaciation suggested hypothalamic dysfunction. Treatment with 2400 rads to the cranium over 2 weeks (Dr. J. S. Scott) considerably resolved the neurological syndrome, and repeat marrow examination showed that a remission had been achieved. 6-Mercaptopurine was started and prednisone was tailed. Within 2 weeks blast cells reappeared in the peripheral blood, rising rapidly in spite of therapy with rubidomycin, cytosine, and thioguanine. Signs reappeared of optic nerve, pontine, and midbrain infiltration, and he died in coma 6 months after the onset of his symptoms.

At necropsy examination there was very heavy leukaemic infiltration of liver, spleen, lymph glands. tonsils, lungs, and major blood vessels. There were leukaemic deposits in the right globe and extraocular tissues and in the right cerebellar hemisphere.

Case 4. A 6-year-old male was admitted with facial and limb pains and swelling of the eyes and neck. Examination revealed a firm left submandibular mass, periorbital swelling, and early exophthalmos. There were no other abnormal findings. Investigations revealed $\mathrm{Hb} 7.0 \mathrm{~g} / 100 \mathrm{ml}$, platelets normal, WBC 5100, neutrophils 1632 . lymphocytes $2754 / \mathrm{mm}^{3}$, small numbers of primitive cells seen; urinary catecholamine excretion $7 \cdot 5 \mu \mathrm{g} / \mathrm{ml}$; skull $x$-rays showed widening of the coronal and sagittal sutures and erosion of the left sphenoidal ridge and lateral orbit; and long bone $x$-rays revealed early leukaemic changes. Marrow samples contained 
$96 \%$ primitive cells, which were PAS and SB negative and had the morphology of undifferentiated stem cells. Treatment with vincristine, prednisone, and 6-mercaptopurine produced little clinical change over the next 3 weeks, though his total white count never exceeded 9500 and the highest peripheral blood blast count was $160 / \mathrm{mm}^{3}$. He finally lapsed into coma and died 8 weeks after the onset of symptoms.

At necropsy examination there was leukaemic involvement of lymph nodes, liver, spleen, kidneys, lungs, thyroid, pancreas, and adrenals. The brain showed malignant infiltration of the optic nerves and retro-orbital tissues, though it was not detected in the Virchow-Robin spaces.

\section{Discussion}

The time sequence in the development of the disease is shown in the Fig. Only in Case 4 was
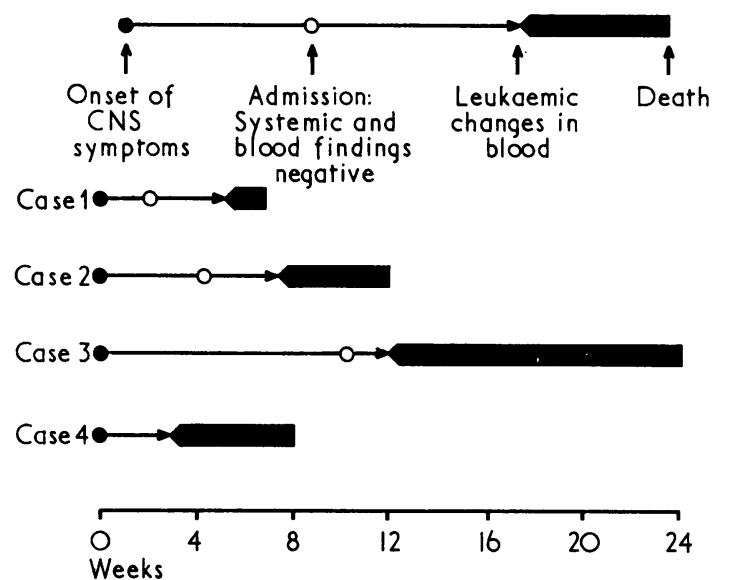

FIG.- Time sequence in the development of the disease.

there no interval elapsing between the appearance of neurological signs and systemic leukaemia. It seems indisputable that in all 4 cases the brain was the site where the leukaemic process first established itself.
Table I shows the cytology of all cases of leukaemia treated at this hospital in the past 12 years. The finding of lymphoblastic cytology in $73 \%$ is in keeping with other series, but most reviews make no distinction between lymphoblastic and acute stem cell leukaemia (Pierce, 1962; Hyman et al., 1965; Evans et al., 1970). Aur et al. (1972) state that at their hospital a diagnosis of acute lymphoblastic leukaemia is made when either stem cells or lymphoblasts predominate in the bone marrow. Cytochemical classifications group these categories together (Hayhoe, Quaglino, and Doll, 1964) but this has been disputed on clinical as well as cytological grounds (Fraumeni, Manning, and Mitus, 1971), and the cases reported here support this view.

Clinical CNS involvement has recently been recorded in 50 to $60 \%$ of cases of lymphoblastic leukaemia (Evans et al., 1970; Melhorn et al., 1970; West et al., 1972), with a median incidence at between 8 and 12 months after initial diagnosis. Improved survival times have led to increasing cerebral involvement in myeloblastic leukaemia (Seligman et al., 1972) and in leukaemic lymphosarcoma (Watanabe et al., 1973). The generally more rapid course of adult reticuloses, however, is reflected in a much lower reported incidence (Phair, Anderson, and Namiki, 1964; Currie and Henson, 1971).

It is therefore of particular interest to find that reports over the past 20 years of leukaemia presenting initially in the CNS (Table II) implicate a wide variety of cytological types, from which lymphoblastic leukaemia is almost excluded. Reports fall into two categories. (a) Those with ocular involvement in the form of global compression, optic nerve infiltration, and occasionally seeding of the uveal tract with secondary glaucoma; (b) those with meningeal involvement with or without signs of diffuse cerebral involvement. Most cases have been associated with simultaneous development of systemic leukaemia, but a few have

TABLE I

Incidence of CNS involvement by cytological type in all cases of acute leukaemia at the Royal Hospital for Sick Children, Glasgow, since 1960

\begin{tabular}{|c|c|c|c|c|c|}
\hline Cell type & No. & $\begin{array}{l}\text { Percentage of } \\
\text { all cell types }\end{array}$ & CNS involvement & $\begin{array}{l}\text { Percentage by } \\
\text { cell type }\end{array}$ & $\begin{array}{c}\text { Median time to } \\
\text { CNS leukaemia (mth) }\end{array}$ \\
\hline $\begin{array}{l}\text { Lymphoblastic } \\
\text { Myeloblastic } \\
\text { Myelomonocytic } \\
\text { Stem cell } \\
\text { Other }\end{array}$ & $\begin{array}{r}97 \\
10 \\
8 \\
4 \\
13\end{array}$ & $\begin{array}{r}73 \cdot 5 \\
7 \cdot 5 \\
6 \cdot 0 \\
3 \cdot 0 \\
10 \cdot 0\end{array}$ & $\begin{array}{r}34 \\
2 \\
0 \\
4 \\
0\end{array}$ & $\begin{array}{c}35 \\
20 \\
\overline{100} \\
-\end{array}$ & $\begin{array}{l}10 \\
\frac{21}{0} \\
-\end{array}$ \\
\hline
\end{tabular}


TABLE II

Acute leukaemia presenting with cerebral involvement: published reports in English since 1953

\begin{tabular}{l|c|c}
\hline \multicolumn{1}{c|}{ Cytological type } & $\begin{array}{c}\text { (A) Eye } \\
\text { involvement }\end{array}$ & $\begin{array}{c}\text { (B) Meningeal } \\
\text { involvement }\end{array}$ \\
\hline $\begin{array}{l}\text { Myeloblastic } \\
\quad \text { Chloromatous }\end{array}$ & 8 & 2 \\
$\begin{array}{l}\text { Nonchloromatous } \\
\text { Myelomonocytic including } \\
\text { reticulosarcoma }\end{array}$ & 5 & $2^{\star}$ \\
$\begin{array}{l}\text { Lymphoblastic including } \\
\text { lymphosarcoma }\end{array}$ & 16 & 0 \\
Undifferentiated stem cell & 3 & 1 \\
\hline Total & 0 & 2 \\
\hline
\end{tabular}

^Includes one case of myeloblastic transformation of chronic granulocytic leukaemia.

preceded it by several months (Lusher, 1964; Borgstedt et al., 1970). Where reticulum cell sarcoma and lymphosarcoma were diagnosed by local biopsy, the marrow diagnosis was respectively monoblastic and lymphoblastic leukaemia. Chloromatous tumours were associated usually with myeloblastic, but occasionally with myelomonocytic, leukaemia. Of 32 cases with initial involvement of the eye, 24 were in non-Caucasian children. Davies and Owor (1965) have pointed out the high incidence of chloroma and other solid reticuloendothelial tumours in East African children, some of which enter a leukaemic phase; and Cavdar et al. (1971) and Mortada (1962, 1968) have drawn attention to the frequency of myelomonocytic leukaemia presenting in this way in Egyptian children. Of the 7 cases reported of diffuse intracerebral involvement at diagnosis (Creskoff, 1953; Lusher, 1964; Kwaan, Pierre, and Long, 1969; Hurwitz, Sutherland, and Walker, 1970; Porter, 1970; Borgstedt et al., 1970), only one was subsequently shown to have lymphoblastic leukaemia (Levine, Winkelstein, and Shadduck, 1973).

These case reports are only a cross-section of leukaemia with CNS involvement from the outset. For example, Pierce (1962) cites one case in a series of 232, Hyman et al. (1965) cites 3 in a series of 55, and Aur et al. (1972) cites 2 out of 110 with signs of cerebral leukaemia at diagnosis. These reviews, however, all group acute stem cell and lymphoblastic leukaemia together, thus the initial occurrence of the latter in the CNS may yet be a distinct rarity. Other reviews, moreover, do not record any instances of this phenomenon (Hardisty and Norman, 1967; Haghbin and Zuelzer, 1965).

The 4 children reported here all had initial brain involvement with rapid systemic spread developing after a variable interval. At the time of diagnosis, however, the striking lack of evidence of systemic leukaemia led to a diagnosis of cerebral tumour in 3 cases. Their leukaemic cells at no time showed any differentiation into either myeloid or lymphoid series, and they were more or less insensitive to cytotoxic therapy. This seems, therefore, to be a distinct pathological process, yet the end result was indistinguishable at necropsy from other forms of acute childhood leukaemia.

The concept of sanctuary areas may therefore be relevant to these cases. It is commonly believed that a neoplastic process establishes itself only by neutralizing a sufficient number of immunocompetent cells to overcome host resistance (Burnet, 1967; Smith, 1968). The brain exercises a relatively weak immune response to neoplastic invasion, lacking the immunocompetent T-lymphocytes that provide surveillance against neoplastic antigenic challenge (Scheinberg, Edelman, and Levy, 1964). Of the 24 reticuloendothelial malignancies recorded by Schneck and Penn (1971) as occurring in renal transplant recipients on longterm immunosuppressive therapy, 11 developed in the brain, suggesting that it is the latter that is most sensitive to such immunosuppression. Thus if, as one might expect, the children reported here exerted a vigorous immune rejection response when first challenged with these very undifferentiated cell lines, then the chance of the leukaemic clone surviving to replicate could depend on access to the more protected (because less immunogenic) environment of the brain.

Smith (1968) has suggested that a tumour arising in an area that is immunologically isolated may achieve self-sustaining growth and become impregnable to immune mechanisms by the time the lymphoreticular apparatus is effectively stimulated. If, as seems probable, systemic leukaemia can arise from extracerebral leakage of malignant cells from CNS infiltrates (Johnson, 1964; Evans et al., 1970; Aur et al., 1972), then the clinical course of these children can be understood. After a period of uninterrupted growth, the leukaemic process first manifested itself in the brain, subsequently spread to extracerebral sites, and was able to overwhelm the previously effective immune defenses of the host.

I thank Dr. M. L. N. Willoughby, Consultant Haematologist, and Dr. J. B. P. Stephenson, Consultant Paediatric Neurologist, for much helpful advice; and Professor J. H. Hutchison and Dr. R. A. Shanks for permission to report cases under their care.

\section{REFERENCES}

Aur, R. J. A., Simone, J. V., Hustu, H. O., and Verzosa, M. S. (1972). A comparative study of central nervous system irradiation and intensive chemotherapy early in remission of childhood acute lymphocytic leukemia. Cancer, 29, 381. 
Borgstedt, A. D., Magill, F. B., Miller, D. R, and Chervin, P. N. (1970). Increased intracranial pressure: initial manifestation of acute leukemia. New York State fournal of Medicine, 70, 2112.

Burnet. F. M. (1967). Immunological aspects of malignant disease. Lancet, 1, 1171

Cavdar, A. O., Arcasoy, A., Goldasoglu, S., and Demirag, B. (1971). Chloroma-like ocular manifestations in Turkish children with acute myelomonocytic leukaemia. Lancet, 1, 680.

Creskoff, A. J. (1953). Leukemia: oddities in onset and course. Medical Clinics of North America, 37, 1747.

Currie, S., and Henson, R. A. (1971). Neurological syndromes in the reticuloses. Brain, 94, 307.

Davies, J. N. P., and Owor, R. (1965). Chloromatous tumours in African children in Uganda. British Medical fournal, 2, 405.

Evans, A. E., Gilbert, E. S., and Zandstra, R. (1970). The increasing incidence of central nervous system leukemia in children. Cancer, 26, 404.

Fraumeni, J. F., Manning, M. D., and Mitus, W. J. (1971). Acute childhood leukemia: epidemiologic study by cell type of 1263 cases at the Children's Cancer Research Foundation in Boston, 1947-1965. Fournal of the National Cancer Institute, 46, 461.

Haghbin, M., and Zuelzer, W. W. (1965). A long-term study of cerebrospinal leukemia. Fournal of Pediatrics, 67, 23.

Hardisty, R. M., and Norman, P. M. (1967). Meningeal leukaemia. Archives of Disease in Childhood, $42,441$.

Hayhoe, F. G. J., Quaglino, D., and Doll, R. (1964). The Cytology and Cytochemistry of Acute Leukaemias. A Study of 140 Cases. (No. 304 M.R.C. Special Report Series). H.M.S.O., London.

Hurwitz, B. S., Sutherland, J. C., and Walker, M. D. (1970). Central nervous system chloromas preceding acute leukemia by one year. Neurology, 20, 771.

Hyman, C. B., Bogle, J. M., Brubaker, C. A., Williams, K., and Hammond, D. (1965). Central nervous system involvement by leukemia in children. I. Relationship to systemic leukemia and description of clinical and laboratory manifestations. Blood, 25, 1.

Johnson, R. E. (1964). An experimental therapeutic approach to L1210 leukemia in mice: combined chemotherapy and central nervous system irradiation. Fournal of the National Cancer Institute, 32, 1333.

Kwaan, H. C., Pierre, R. V., and Long, D. L. (1969). Meningeal involvement as first manifestation of acute myeloblastic transformation in chronic granulocytic leukemia. Blood, 33, 348 .

Levine, G. A., Winkelstein, A., and Shadduck, R. K. (1973). CNS involvement as the initial manifestation of acute leukemia. Cancer, 31, 959.

Lusher, J. M. (1964). Chloroma as a presenting feature of acute leukaemia. A report of two cases in children. American fournal of Diseases of Children, 108, 62.

Melhorn, D. K., Gross, S., Fisher, B. J., and Newman, A. J. (1970). Studies on the use of prophylactic intrathecal amethopterin in childhood leukemia. Blood, 36, 55.

Mortada, A. (1962). Orbital reticulum-cell sarcoma with monocytic leukemia: report of two cases. Archives of Ophthalmology, 67, 572.

Mortada, A. (1968). Bilateral exophthalmos and lymphoblastic aleukaemic leukaemia. British fournal of Ophthalmology, 52, 68.

Phair, J. P., Anderson, R. E., and Namiki, H. (1964). The central nervous system in leukemia. Annals of Internal Medicine, 61, 863.

Pierce, M. I. (1962). Neurologic complications in acute leukemia in children. Pediatric Clinics of North America, 9, 425.

Pinkel, D., Simone, J., Hustu, H. O., and Aur, R. J. A. (1972) Nine years experience with 'total therapy' of childhood acute lymphocytic leukemia. Pediatrics, 50, 246.

Porter, E. A. (1970). Acute leukaemia presenting with papilloedema: case report. New Zealand Medical fournal, 71, 138.

Scheinberg, L. C., Edelman, F. L., and Levy, W. A. (1964). Is the brain an immunologically privileged site? Archives of Neurology, 11, 248.

Schneck, S. A., and Penn, I. (1971). De-novo brain tumours in renal-transplant recipients. Lancet, 1, 983.

Seligman, B. R., Rosner, F., Lee, S. L., and Ritz, N. D. (1972). Clinical meningeal leukemia in acute myelocytic leukemia. New York State fournal of Medicine, 72, 1855.

Smith, R. T. (1968). Tumor-specific immune mechanisms. New England fournal of Medicine, 278, 1326.

Watanabe, A., Sullivan, M. P., Sutow, W. W., and Wilbur, J. R (1973). Undifferentiated lymphoma, non-Burkitt's type. American Fournal of Diseases of Children, 125, 57.

West, R. J., Graham-Pole, J., Hardisty, R. M., and Pike, M. C. (1972). Factors in pathogenesis of central-nervous-system leukaemia. British Medical fournal, 3, 311.

Correspondence to Dr. J. Graham Pole, Department of Child Health, Royal Hospital for Sick Children, Glasgow G3 8SJ. 